\title{
Inhibition of LPMOs by Fermented Persimmon Juice
}

\author{
Radina Tokin ${ }^{1}$, Johan Ørskov Ipsen ${ }^{1}$, Mahesha M. Poojary ${ }^{2} \mathbb{D}$, Poul Erik Jensen ${ }^{2} \mathbb{D}$, Lisbeth Olsson ${ }^{3}$ \\ and Katja Salomon Johansen $1, *$ (D)
}

1 Department of Geoscience and Natural Resource Management, University of Copenhagen, DK-1958 Frederiksberg, Denmark; rato@ign.ku.dk (R.T.); jip@ign.ku.dk (J.Ø.I.)

2 Department of Food Science, University of Copenhagen, DK-1958 Frederiksberg, Denmark; mahesha@food.ku.dk (M.M.P.); peje@food.ku.dk (P.E.J.)

3 Division of Industrial Biotechnology, Department of Biology and Biological Engineering, Chalmers University, 41296 Göteborg, Sweden; lisbeth.olsson@chalmers.se

* Correspondence: ksj@ign.ku.dk; Tel.: +45-3533-3706

Citation: Tokin, R.; Ipsen, J.Ø.; Poojary, M.M.; Jensen, P.E.; Olsson, L.; Johansen, K.S. Inhibition of LPMOs by Fermented Persimmon Juice. Biomolecules 2021, 11, 1890. https:// doi.org/10.3390/biom11121890

Academic Editor: Andrzej Szczurek

Received: 5 November 2021

Accepted: 13 December 2021

Published: 16 December 2021

Publisher's Note: MDPI stays neutral with regard to jurisdictional claims in published maps and institutional affiliations.

Copyright: (c) 2021 by the authors. Licensee MDPI, Basel, Switzerland. This article is an open access article distributed under the terms and conditions of the Creative Commons Attribution (CC BY) license (https:// creativecommons.org/licenses/by/ $4.0 /)$.

\begin{abstract}
Fermented persimmon juice, Kakishibu, has traditionally been used for wood and paper protection. This protective effect stems at least partially from inhibition of microbial cellulose degrading enzymes. The inhibitory effect of Kakishibu on lytic polysaccharide monooxygenases (LPMOs) and on a cocktail of cellulose hydrolases was studied, using three different cellulosic substrates. Dose dependent inhibition of LPMO activity by a commercial Kakishibu product was assessed for the well-characterized LPMO from Thermoascus aurantiacus TaAA9A, and the inhibitory effect was confirmed on five additional microbial LPMOs. The model tannin compound, tannic acid exhibited a similar inhibitory effect on TaAA9A as Kakishibu. It was further shown that both polyethylene glycol and tannase can alleviate the inhibitory effect of Kakishibu and tannic acid, indicating a likely mechanism of inhibition caused by unspecific tannin-protein interactions.
\end{abstract}

Keywords: LPMO; cellulase; Kakishibu; inhibition; tannins; PEG

\section{Introduction}

Persimmon, or kaki, from the tree species Diospyros kaki and Diospyros virginiana, is a fruit with large significance to Asian culture, cuisine, and folk medicine. Phytochemicals, such as proanthocyanidins, flavonoids, tannins, and other polyphenols, are among the important bioactive constituents of persimmon [1,2]. Astringent persimmon fruit (unripe fruits) is used to produce the fermented persimmon juice, also called Kakishibu [3]. Since ancient times, the juice has been used for its antimicrobial, waterproofing, and dyeing properties, utilized for wood, fabric, and paper treatments. The use of Kakishibu in Asian folk medicine stemmed from its high polyphenolic content, with applications such as a neutralizing agent against proteinaceous snake toxins [4].

It is now known that fruit astringency stems from the presence of tannins, which are able to interfere with and precipitate salivary enzymes, creating a bitter taste and a dry sensation [5]. Unspecific tannin-protein interactions have long been known to have a negative effect on enzyme activity, which can be costly for industrial processes. Polyphenols from astringent persimmon have been reported to inhibit various enzymes, among which are cellulase [6], amylase and glucosidase [4], and tyrosinase [7].

Inhibition of Tricoderma viride cellulases by persimmon fruit has been reported by Mandels and Reese already in 1960 [6]. A part of this activity, which at that time was termed C1-activity, is now attributed to a relatively new class of enzymes, called lytic polysaccharide monooxygenases (LPMO). In light of this, we set out to re-evaluate the inhibitory effect of persimmon juice on cellulolytic activities. The presented paper investigates the commercially available persimmon juice, Kakishibu, for its inhibitory properties towards a cellulolytic enzyme cocktail and LPMOs. 


\section{Materials and Methods}

\subsection{Materials and Chemicals}

Fermented persimmon juice (Kakishibu) was purchased from Tomiyama Inc (Kyoto, Japan). Azurine-cross-linked-hydroxyethyl cellulose (AZCL-HEC), cellooligosaccharides and tannase were purchased from Megazyme (Ayr, Scotland). The commercial enzyme cocktail Celluclast, Avicel PH-101, para-hydroxybenzoic acid hydrazide (PAHBAH), tannic acid, ascorbic acid, gallic acid, phenolic compounds, polyethylene glycol 20,000 (PEG), and other reagents were purchased from Sigma-Aldrich (Søborg, Denmark). Phosphoric acid swollen cellulose (PASC) was prepared from Avicel [8], followed by Milli-Q washing.

\subsection{Characterization}

The polyphenolic fingerprint of Kakishibu was analyzed using liquid chromatographymass spectrometry (LC-ESI-MS/MS, Thermo Fisher Scientific, Waltham, MA, USA), as described previously [9]. In brief, Kakishibu was filtered through a $0.22 \mu \mathrm{m}$ membrane filter, in order to remove aggregated polyphenols, and injected into a Zorbax Eclipse Plus C-18 column (1.8 $\mu \mathrm{m}$ particle size, Agilent Technologies, Glostrup, Denmark) fitted to a UHPLC system, combined with an Orbitrap Q Exactive high-resolution mass spectrometer (Thermo Fisher Scientific, Waltham, MA, USA). The analytes were eluted using $0.1 \% v / v$ formic acid (mobile phase A) and acetonitrile (mobile phase B). The polyphenols were identified by comparing the peak properties with those of authentic polyphenolic standards.

\subsection{Enzyme Production and Purification}

Three LPMOs and one $\beta$-glucosidase (BG) were kindly provided by Novozymes A/S-fungal LPMOs from Thermoascus aurantiacus (TaAA9A) [10], Thielavia terrestris (TtAA9E) [10], Neurospora crassa (NcAA9E) [11,12], and a BG from Aspergillus fumigatus, AfBG (EAL88289) [13]. These LPMOs were heterologously expressed in A. oryzae and purified as described elsewhere [14,15]. AfBG was heterologously expressed in A. oryzae as described before [16]. Two LPMOs from Podospora anserina, PaAA9E and PaAA9H [17], were cloned and produced in P. pastoris as described previously [18]. One bacterial LPMO, TfLPMO10A [19], from Thermobifida fusca, was heterologously expressed in E. coli and purified by ion exchange, followed by size-exclusion chromatography, as described previously [20]. The concentration of all proteins was determined by amino acid analysis according to [21]. For minimal amounts of free copper in the experimental assays, holo-LPMO samples were prepared by incubating the proteins overnight at $4{ }^{\circ} \mathrm{C}$ with sub-stoichiometric amounts of $\mathrm{CuSO}_{4}$ (75\% of LPMO) [22].

\subsection{Activity and Inhibition Assays}

All enzymatic activity assays were carried out at $50{ }^{\circ} \mathrm{C}$ with $1000 \mathrm{rpm}$ shaking in an Eppendorf thermomixer, in $50 \mathrm{mM}$ citrate/phosphate buffer ( $\mathrm{pH}$ 6), unless specified otherwise.

\subsubsection{Kakishibu-Impregnated Filter Paper}

The inhibitory effect of Kakishibu on cellulose-degrading enzymes was assessed using a commercial enzyme cocktail, Celluclast, a BG and an LPMO. Filter paper discs (Whatman P81, $2.5 \mathrm{~cm}$ diameter; Maidstone, England) were impregnated by Kakishibu solutions and allowed to air-dry overnight. The experiment was performed under fixed protein content $(2 \mathrm{mg} / \mathrm{g}$ cellulose $)$, in the presence of ascorbate $(2 \mathrm{mM})$. The filter paper discs were incubated in 6-well culture plates with Celluclast, supplemented with AfBG $(10 \%)$, or Celluclast and AfBG, supplemented with TaAA9A (50\%). The plates were incubated for $72 \mathrm{~h}$ in an incubator (New Brunswick Innova 44R; Eppendorf Nordic, Hørsholm, Denmark) at $50{ }^{\circ} \mathrm{C}$ and $120 \mathrm{rpm}$. After a visual inspection, the supernatant was collected and filtered before further analysis (PES, $0.22 \mu \mathrm{m}$ pore size; Merck Millipore, Tullagreen, Ireland). 


\subsubsection{Reducing-End Quantification}

The extent of filter paper breakdown was then assessed with a reducing-end detection assay, utilizing the PAHBAH reagent [23]. The assay conditions were as described previously [15]. Briefly, the samples were mixed with the reaction solution $(15 \mathrm{mg} / \mathrm{mL}$ PAHBAH in $0.18 \mathrm{M}$ potassium sodium tartrate), followed by incubation at $95^{\circ} \mathrm{C}$ for $10 \mathrm{~min}$. Sample absorbance was measured at $410 \mathrm{~nm}$ in a plate reader (BioTek Synergy H1; Agilent Technologies, Glostrup, Denmark). Reducing-end quantification was done on the basis of a glucose standard curve. Data are presented as the percentage of cellulose conversion (saccharification yield), using the known amount of polymeric substrate added.

\subsubsection{Chromogenic AZCL-HEC Substrate}

The LPMO TaAA9A was tested further for its susceptibility to inhibition on the chromogenic substrate AZCL-HEC (Megazyme; Ayr, Scotland). Samples containing TaAA9A $(1 \mu \mathrm{M})$, AZCL-HEC $(0.4 \mathrm{mg} / \mathrm{mL})$, and ascorbate $(2 \mathrm{mM})$ were incubated for $15 \mathrm{~h}$, in the absence and presence of PEG $(1 \mathrm{~g} / \mathrm{L})$. Two inhibitory components were tested in a dose-dependent manner-Kakishibu (0-10 $\mathrm{mg} \mathrm{DW} / \mathrm{mL})$ and tannic acid, a persimmon component $(0-4 \mathrm{mM})$.

Apart from PEG, the alleviation of inhibition was tested by the addition of tannase enzyme (EC 3.1.1.20), from Aspergillus ficuum (purchased from Megazyme). Samples containing TaAA9A $(1 \mu \mathrm{M})$, AZCL-HEC $(0.4 \mathrm{mg} / \mathrm{mL})$, Kakishibu $(5.2 \mathrm{mg} \mathrm{DW} / \mathrm{mL})$, or tannic acid $(1 \mathrm{mM})$ were incubated for $20 \mathrm{~h}$ at $30^{\circ} \mathrm{C}$, in the absence and presence of tannase $(0.16 \mathrm{mg} / \mathrm{mL})$. Gallic acid, which is the tannase breakdown product from tannic acid, was used as an LPMO reductant (2 mM), in order to obtain a positive control sample [24].

All reactions, performed on AZCL-HEC, were stopped by centrifugation through filter plates with a $0.22 \mu \mathrm{m}$ pore size (Millipore), followed by absorbance measurements at $590 \mathrm{~nm}$ in a plate reader (BioTek Synergy H1).

\subsubsection{LPMO Inhibition Susceptibility}

The promiscuity of inhibition by Kakishibu was assessed on the cellulosic substrate PASC for five LPMOs from fungal origin (TaAA9A, TtAA9E, NcAA9E, PaAA9E, and $\mathrm{PaAA} 9 \mathrm{H}$ ) and one from bacterial origin (TfLPMO10A). Samples containing PASC $(5 \mathrm{mg} / \mathrm{mL})$, holo-LPMO $(1 \mu \mathrm{M})$, and ascorbate $(2 \mathrm{mM})$ were incubated in a microtiter plate, with and without Kakishibu (1 mg DW/mL). Addition of PEG $(1 \mathrm{~g} / \mathrm{L})$ was used to test its protective effect, due to the known interaction of PEG with polyphenols. Additional samples in the presence of $\mathrm{H}_{2} \mathrm{O}_{2}(100 \mu \mathrm{M})$ were obtained for TaAA9A, to assess any potential interaction between this LPMO co-substrate and Kakishibu. The microtiter plates were incubated for $12 \mathrm{~h}$. The reaction was stopped by filtration through filter plates with a $0.22 \mu \mathrm{m}$ pore size (Millipore), using a vacuum manifold. The breakdown of substrate was assessed by HPAEC-PAD and compared to pure oligosaccharide standards.

\subsection{Data Analysis}

Unless otherwise specified, all measurements were obtained with a minimum of three technical replicates, analyzed and graphed by statistical software Origin 2020 (Northampton, MA, USA).

\section{Results}

The protective effect of Kakishibu juice on enzymatic cellulose degradation was assessed using cellulosic filter paper as substrate. Non-impregnated and Kakishibuimpregnated filter paper discs were subjected to hydrolysis by the commercial enzyme cocktail, Celluclast, in the absence and presence of Thermoascus aurantiacus LPMO, TaAA9A (Figure 1). The addition of Celluclast to the non-impregnated paper discs resulted in visible paper disintegration (Figure 1a) and a cellulose conversion of $5.4 \%$, quantified using the reducing end PAHBAH assay (Figure 1b). Substrate breakdown was further boosted by the addition of the LPMO and ascorbate as its reductant, reaching a $7.6 \%$ conversion. The 
extent of cellulose conversion by the enzyme mixtures was reduced for all filter paper samples impregnated with the persimmon juice, with the highest inhibition observed for the highest Kakishibu dose $(208 \mathrm{mg} / \mathrm{mL})$. Furthermore, the expected synergy upon TaAA9A addition was absent for the impregnated samples, suggesting a strong LPMO inhibition in the presence of Kakishibu.

a

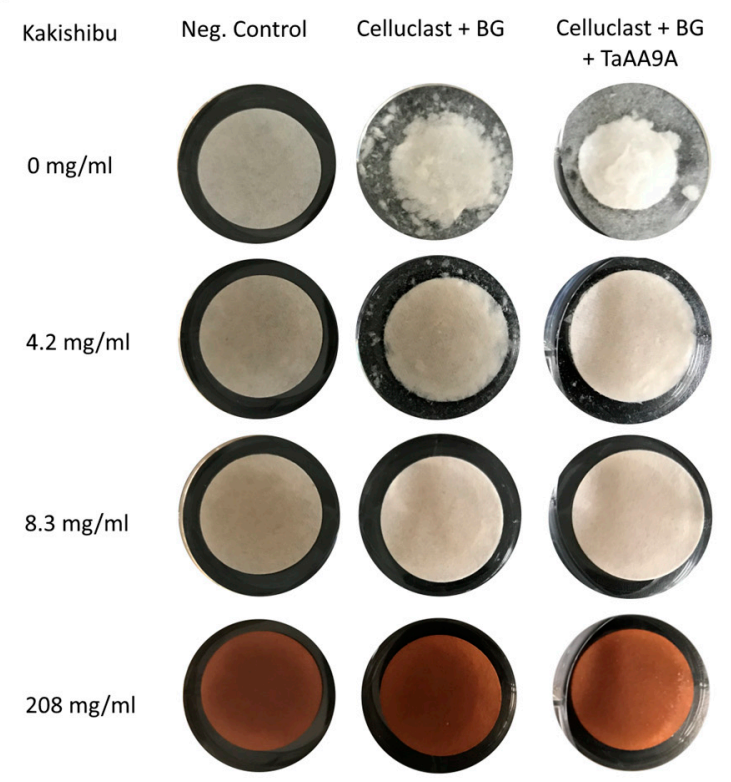

b

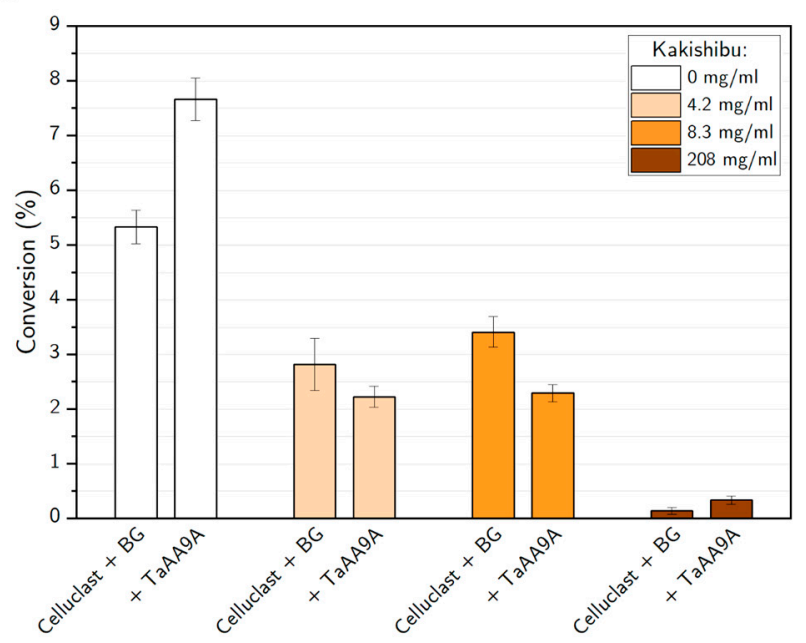

Figure 1. Paper impregnation with Kakishibu inhibits cellulose breakdown. (a) The effect of filter paper impregnation with increasing concentrations of Kakishibu was tested with Celluclast, supplemented with AfBG, with and without addition of Thermoascus aurantiacus LPMO, TaAA9A. Experiments were performed at $50{ }^{\circ} \mathrm{C}$, under fixed protein content $(2 \mathrm{mg} / \mathrm{g}$ cellulose), in the presence of ascorbate as LPMO reductant (2 $\mathrm{mM})$. (b) Quantification of cellulose breakdown from (a), measured by a reducing end PAHBAH detection assay. Data are shown after subtraction of negative control without enzyme addition and plotted as a percentage of cellulose conversion. Error bars represent propagated standard deviations.

To assess the extent of LPMO inhibition, concentration-response for Kakishibu and the model tannin compound, tannic acid, were obtained with TaAA9A on the chromogenic substrate AZCL-HEC, in the presence of ascorbate (Figure 2). The presence of Kakishibu, as well as tannic acid, inhibited the LPMO in a dose-dependent manner, with a more pronounced effect for persimmon juice (Figure 2a). In both cases, the inhibition was successfully alleviated by the addition of the non-ionic polymer PEG, which is known to bind polyphenols in solution [25] and has been shown to protect from their negative effect on other types of enzymes [26-28].

In addition to PEG-polyphenol interaction, we tested if the observed negative effect on the LPMO could be alleviated by enzymatic treatment. Tannases (tannin acyl hydrolases) are enzymes that break down gallotannins, ellagitannins, and complex tannins by the hydrolysis of their ester bonds [29]. Specifically, we investigated whether degradation of Kakishibu tannins and tannic acid could also rescue the LPMO from inhibition. An added benefit to tannin hydrolysis would be the steady production of gallic acid, a compound which is a well-known activator for LPMOs [24]. Figure 3a shows the effect of tannase or gallic acid addition to the inhibited TaAA9A. In the absence of PEG, the presence of tannase was only able to alleviate the inhibition by tannic acid, while the LPMO remained inactive in the presence of Kakishibu. The inability of tannase to alleviate the apparent polyphenol inhibition by Kakishibu may stem from the complexity of the juice's tannins and other polyphenol constituents. In the presence of PEG and the absence of a reductant, the addition of tannase enzyme alleviated LPMO inhibition from both Kakishibu and tannic acid. The positive effect of tannase addition was likely achieved through the breakdown 
of tannic acid and Kakishibu tannins into their gallic acid monomer. Figure $3 b$ illustrates that a dose-dependent TaAA9A-activation can be obtained, when gallic acid is used as the LPMO reductant. In addition to the removal of inhibitory polyphenols, the gradual release of gallic acid from tannase-mediated tannin hydrolysis could provide a steady supply of LPMO reductant (Figure 3c).
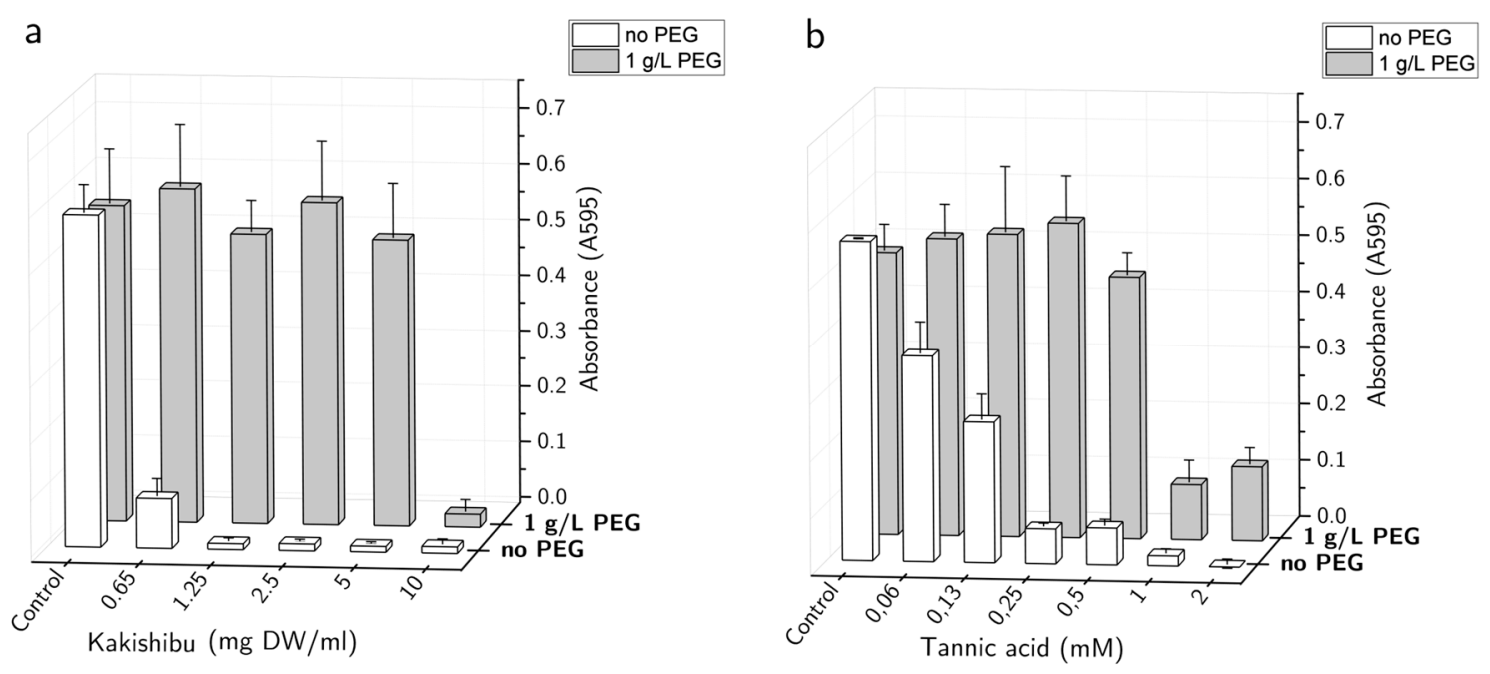

Figure 2. Inhibition of LPMO by (a) Kakishibu and (b) tannic acid. Increasing concentrations of the inhibitors were tested on TaAA9A $(1 \mu \mathrm{M})$. Data are shown in the absence and presence of PEG $(1 \mathrm{~g} / \mathrm{L})$, to assess the protective effect through polyphenol precipitation. Results were obtained at $50{ }^{\circ} \mathrm{C}$, with the chromogenic substrate AZCL-HEC $(0.4 \mathrm{mg} / \mathrm{mL})$ in the presence of ascorbate as a reductant $(2 \mathrm{mM})$, by measuring absorbance at $595 \mathrm{~nm}$.

Interestingly, TaAA9A exhibited higher activity in the PEG-treated Kakishibu samples, compared to tannic acid samples (Figure 3a). This could be explained by the presence of phenolic compounds in the juice that are able to further boost LPMO activity, after the removal of larger polyphenols from solution. Filtered Kakishibu was characterized in terms of the juice's small phenolic compound content by LC-MS (Table A1). Constituents present in plant biomass mixtures have long been known to be sufficient for the activation of LPMOs [24].

In order to assess if Kakishibu is able to inhibit LPMOs from other microbial sources, we tested LPMO inhibition during degradation of the amorphous cellulosic substrate PASC. Figure 4 shows the results of inhibition for six microbial LPMOs: TaAA9A from Thermoascus aurantiacus [10], NcAA9E from Neurospora crassa [11], PaAA9E and PaAA9H from Podospora anserina [17], TtAA9E from Thielavia terrestris [10], and the bacterial TfLPMO10A from Thermobifida fusca [19].

HPAEC chromatograms of the LPMO product profiles were obtained in the absence (black) and presence (red) of Kakishibu. Once again, PEG was used to alleviate the inhibition (green). The LPMO-specific oxidation products were observed for each enzyme, despite differences in the product profiles between the tested LPMOs. The weakest inhibition by Kakishibu on this cellulosic substrate was observed for TaAA9A (Figure 4a). The other five LPMOs displayed higher susceptibility to Kakishibu inhibition, when compared to TaAA9A, with the bacterial LPMO, TfLPMO10A, exhibiting almost complete inhibition (Figure 4f). In all cases, addition of PEG protected LPMO activity to varying extents, which was consistent with the previously obtained results (Figures 2 and 3a).

In addition to oxygen, various LPMOs have been reported to utilize $\mathrm{H}_{2} \mathrm{O}_{2}$ for polysaccharide breakdown [30-32]. Inhibition of TaAA9A by Kakishibu was, therefore, also assessed in the presence of $\mathrm{H}_{2} \mathrm{O}_{2}$ (Figure A1). Both LPMO activity and the inhibition by Kakishibu remained unchanged upon addition of the co-substrate. 
a

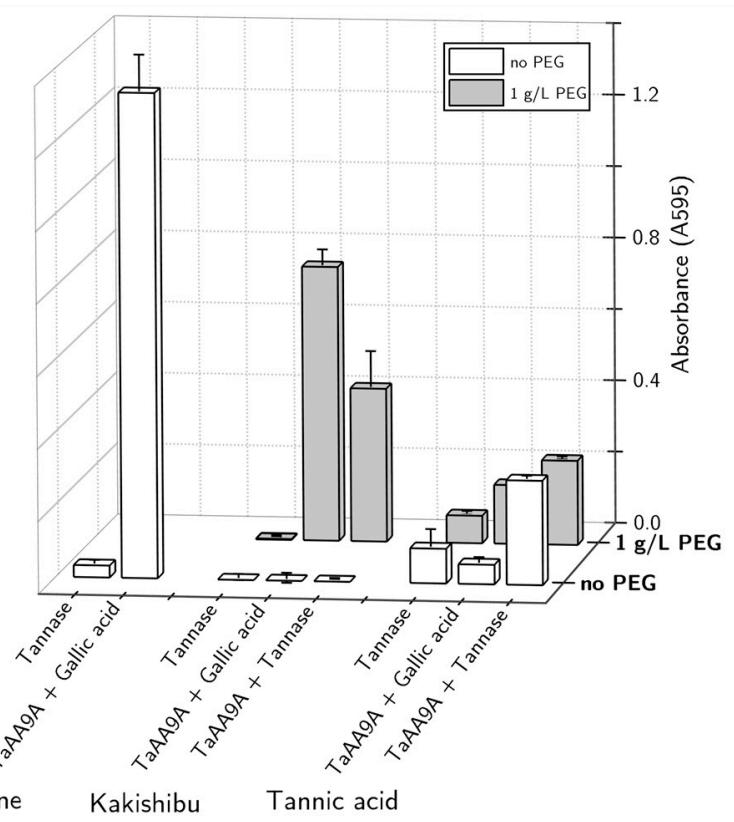

b

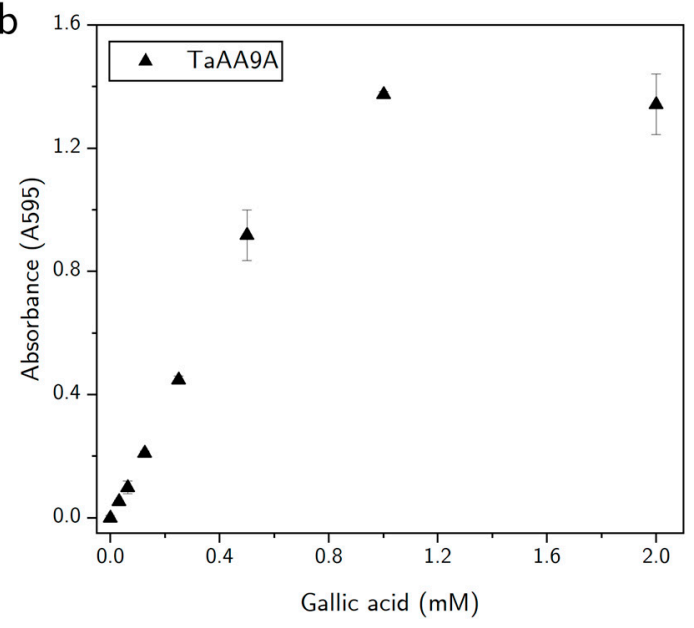

c

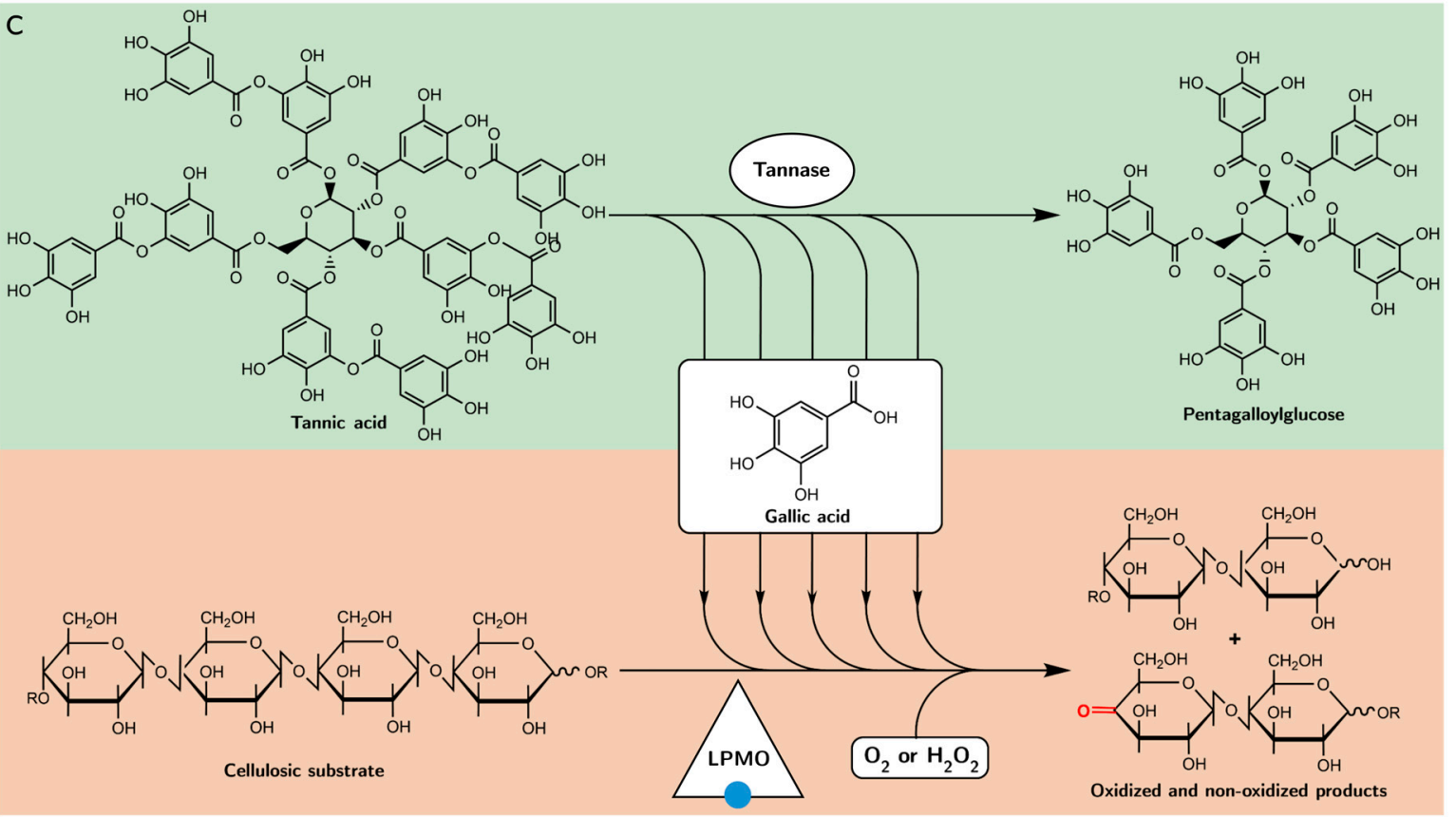

Figure 3. LPMO activation and protective effect of tannase enzyme. (a) Effect of tannase enzyme $(0.16 \mathrm{mg} / \mathrm{mL}) \mathrm{or}$ gallic acid $(2 \mathrm{mM})$ on the inhibition of TaAA9A $(1 \mu \mathrm{M})$ by Kakishibu $(5.2 \mathrm{mg} / \mathrm{mL})$ and tannic acid $(1 \mathrm{mM})$. Data are shown in the absence and presence of PEG $(1 \mathrm{~g} / \mathrm{L})$. Results were obtained with AZCL-HEC $(0.4 \mathrm{mg} / \mathrm{mL})$ at $30{ }^{\circ} \mathrm{C}$, by measuring absorbance at $595 \mathrm{~nm}$. The activity of TaAA9A in the presence of gallic acid, without the addition of inhibitor, is shown as a positive control. (b) Concentration-response curve of TaAA9A $(1 \mu \mathrm{M})$ activation by gallic acid, during AZCL-HEC breakdown $(0.4 \mathrm{mg} / \mathrm{mL})$ at $30{ }^{\circ} \mathrm{C}$. (c) Hydrolysis of tannins by tannase enzyme can result in the steady production of gallic acid, which can activate the LPMO for degradation of polysaccharides, while alleviating inhibition. 

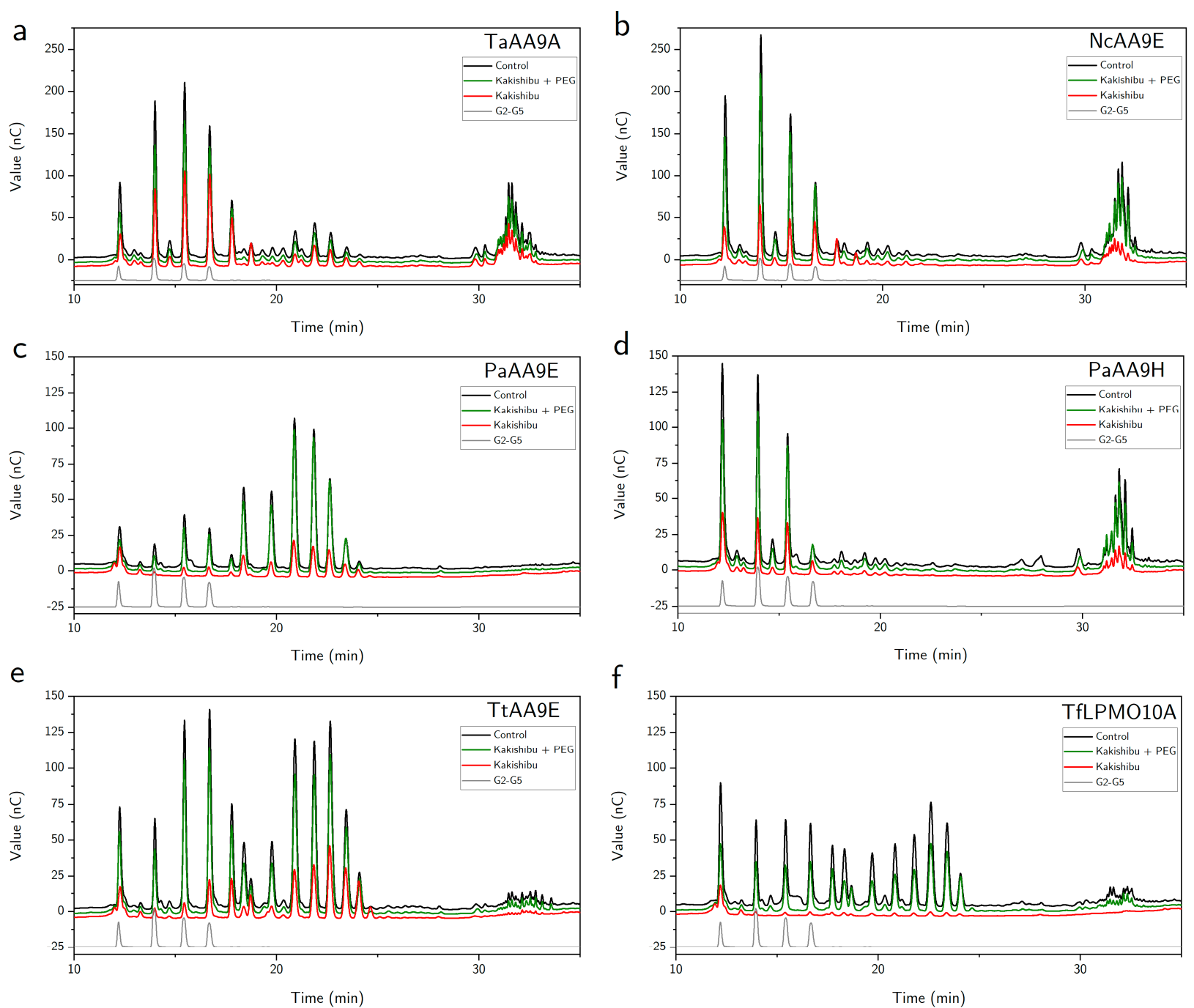

Figure 4. HPAEC chromatograms of LPMO inhibition by Kakishibu. The effect of Kakishibu (1 mg/mL) was assessed during degradation of PASC $(5 \mathrm{mg} / \mathrm{mL})$ by LPMOs $(1 \mu \mathrm{M})$ : (a) TaAA9A; (b) NcAA9E; (c) PaAA9E; (d) PaAA9H; (e) TtAA9E; (f) TfLPMO10A. Data are shown for LPMO positive controls without inhibitor (black), Kakishibu inhibition (red) and Kakishibu in the presence of PEG (green). No chromatographic peaks were detected in Kakishibu negative control on this scale and it was, therefore, omitted for the purpose of clarity. Experiments were performed at $50{ }^{\circ} \mathrm{C}$, with ascorbate $(2 \mathrm{mM})$ as LPMO reductant. The representative chromatograms show results of the analysis of soluble sugar products by HPAEC-PAD. Non-oxidized products (cellobiose-cellopentaose) appear in the range 12-17 min, confirmed by pure standards (G2-G5, grey). C1-oxidized products are expected to be in the range 18-25 min, while C4- and mixed-oxidation products in the range $30-35 \mathrm{~min}$.

\section{Discussion}

The fermented juice of unripe persimmon fruit, Kakishibu has been used since ancient times and is nowadays still utilized for the treatment of natural materials, such as textile, paper, and wood, due to its protective properties. Indeed, the impregnation of filter paper with Kakishibu successfully protected it from cellulolytic enzyme degradation by a commercial cellulase cocktail and an LPMO (Figure 1). The negative effect of Kakishibu was more strongly pronounced for the LPMO, as seen in the complete absence of synergy with the cellulase mixture (Figure $1 b$ ). The protective effect of the persimmon juice has been attributed to its high polyphenolic content, which has been shown to serve as a neutralizing agent for proteinaceous snake toxin [4] and has been reported to have enzyme deactivating properties against cellulase [6,33], alpha-amylase and alpha-glucosidase [34], and copper-dependent tyrosinase [7]. In addition to the large polyphenolic constituents 
with potential enzyme-deactivating properties, smaller phenolic compounds, including tannic acid, have also been reported to be cellulase deactivators or inhibitors $[35,36]$. Both Kakishibu juice and tannic acid exhibited a dose-dependent negative effect on LPMO activity, when acting on the chromogenic substrate AZCL-HEC (Figure 2a,b, respectively). It is known that in oxidative conditions polyphenols can polymerize or condense to produce adducts with low solubility and high affinity for proteins [37]. A chemical oxidation in the presence of free copper ions can cause similar changes that would, ultimately, result in polymerization products with a potential for protein aggregation. It is, therefore, possible that LPMO inhibition by Kakishibu may be affected by such chemical oxidation in the reaction mixture - an idea that was proposed by Mandels and Reese in 1962 [33]. In addition to chemical oxidation, the oxidative environment inherent to the LPMO enzyme itself could further potentiate polyphenol aggregation.

The negative effect of Kakishibu and tannic acid on LPMO activity was successfully alleviated by the addition of PEG to the reaction mixture (Figure 2). Non-ionic surfactants, such as PEG, have long been known to alleviate non-productive interactions of enzymes with tannins and lignin [26-28]. It has been reported that the presence of PEG can reduce the adsorption of cellulases to lignin, leading to improved cellulose breakdown [38]. LPMO activity was also successfully alleviated by an enzyme-driven tannin breakdown, with the help of tannase (Figure 3a). In light of the addition of LPMOs in cellulolytic cocktails, the applicability of enzymes, such as tannases, can go beyond rescuing cellulolytic enzymes from tannin precipitation. Tannase activity breaks down gallotannins, which can provide a steady supply of gallic acid-a compound that is a well-documented reductant for LPMOs (Figure 3b,c) [24]. The enzymatic alleviation of inhibition from tannins has already been described for commercial applications in patents, such as one relating to biomass breakdown, involving tannases [39]. LPMO activation can also be achieved by the coupled reaction with polyphenol oxidase, which produces phenolics with LPMO-activating properties [40]. Combinatorial studies of LPMOs with tannase and polyphenol oxidase enzymes can, therefore, shed light on the industrial utilization of lignin- and tannin-rich substrates.

We observed Kakishibu's negative effect on six LPMOs from other microbial sources, which exhibited a varying extent of inhibition during degradation of the cellulosic substrate PASC (Figure 4). Once again, alleviation of LPMO inhibition was successfully achieved with the addition of PEG. In a recent study, a polyphenolic inhibitor from an extract of cinnamon, cinnamtannin B1, was shown to bind to the surface of an LPMO [9]. In this study, TaAA9A was reported to have lower susceptibility to inhibition by the cinnamon extract during PASC degradation, in contrast to TfLPMO10A, which showed the highest. This is consistent with the results obtained here, in which TaAA9A was less affected by Kakishibu during PASC breakdown (Figure 4a) and TfLPMO10A exhibited the highest susceptibility (Figure 4f). Although tannin-protein interaction is largely considered to be unspecific, differences in LPMO susceptibility to inhibition by Kakishibu may be due to underlying properties, such as protein structure and charge, as well as experimental conditions. The binding of polyphenolic compounds to proteins is of ionic and hydrogenbonding nature [41]. Owing to this nature, the interaction would be affected by factors, such as the protein's surface-charge distribution (i.e., $p I$ ), its MW, the size of the polyphenols, and the $\mathrm{pH}$ and ionic strength of the buffer used, which are well-known to affect proteinpolyphenol interaction and aggregation [42-44]. It is well-known that polyphenols can precipitate one protein, even when another protein is present in a large excess [45]. This can be a problem in industrial processes, such as lignocellulose breakdown, where the presence of tannins and lignin would disproportionately affect certain enzymatic components more than others. TfLPMO10A showed the highest susceptibility to Kakishibu inhibition on PASC (Figure 4f). In addition to its lower molecular weight than the other tested LPMOs, this enzyme was the only one produced in a bacterial expression host. This would result in a protein surface lacking glycosylations, compared to the rest of the fungally expressed LPMOs. Such enzyme-specific binding and inhibition for structurally related proteins has been reported previously for tannic acid and carbohydrate active enzymes [28]. The 
binding affinity of tannic acid was shown to differ between cellulases, endoglucanases, and BGs even within the same enzyme families.

In biological or industrial settings, the presence of complex mixtures of redox-active compounds and reactive oxygen species would ultimately have an effect on LPMO activity. The mechanistic elucidation of LPMO activity is still underway and in addition to oxygen, hydrogen peroxide has also been reported as an LPMO co-substrate [30]. This co-substrate did not affect TaAA9A activity and inhibition under the tested conditions (Figure A1), which is an indication that Kakishibu inhibition did not stem from potential $\mathrm{H}_{2} \mathrm{O}_{2}$-scavenging properties of the juice. A number of small phenolic compounds were detected in Kakishibu juice (Table A1), among which is the well-known LPMO reductant gallic acid, as well as catechin, taxifolin, and quercetin, which have also been reported as LPMO activators [9]. The positive effect of complex biomass mixtures has been reported previously, such as TaAA9A activation by pretreated corn stover [24], as well as activation by pretreated wheat straw for T. reesei and S. marcescens LPMOs [46]. Furthermore, a recent study reported both inhibition and activation of another cellulose-active LPMO from $L$. similis by a number of methanolic and aqueous plant extracts [9].

Further investigations of different experimental conditions, tannins, and carbohydrateactive enzymes may provide valuable knowledge for the development of optimal enzymatic cocktails, tailored for feedstocks with particular phenolic content. Indeed, in large companies today, the current development of enzyme products is becoming more oriented towards customization for specific industrial applications and conditions.

Author Contributions: Conceptualization, R.T. and K.S.J.; methodology, R.T., M.M.P. and J.Ø.I.; writing-original draft preparation, R.T.; writing—review and editing, P.E.J., L.O. and K.S.J.; visualization, R.T.; supervision, P.E.J. and K.S.J.; project administration, K.S.J.; funding acquisition, K.S.J. All authors have read and agreed to the published version of the manuscript.

Funding: This research was funded by The Novo Nordisk Foundation (Grant number NNF17SA0027704 to Katja Salomon Johansen).

Acknowledgments: We would like to thank Novozymes for providing the enzyme samples TaAA9A, NcAA9E, and TtAA9E for the study. A special acknowledgement also to J-G. Berrin and S. Grisel for providing enzyme samples PaAA9E and PaAA9H. We are very thankful for the collaboration with Danish Technical University, and would like to, specifically, thank A. B. Bertelsen and M. Nørholm for producing TfLPMO10A. We would also like to acknowledge A. Peciulyte for her relevant scientific contributions prior to this study.

Conflicts of Interest: The authors declare no conflict of interest.

\section{Appendix A}

Table A1. Phenolic compounds present in Kakishibu, identified by LC-ESI-MS/MS. All compounds were confirmed by pure standards.

\begin{tabular}{cccccc}
\hline Compound & $\begin{array}{c}\text { Molecular } \\
\text { Formula }\end{array}$ & $\begin{array}{c}\text { RT } \\
(\mathbf{m i n})\end{array}$ & $\begin{array}{c}\text { Accurate Mass } \\
{[\mathbf{M}-\mathbf{H}]^{-}}\end{array}$ & $\begin{array}{c}\text { Mass Error } \\
(\mathbf{p p m})\end{array}$ & Fragments $\boldsymbol{m} / \boldsymbol{z}$ (Relative Abundance) \\
\hline$p$-hydroxybenzoic acid & $\mathrm{C}_{7} \mathrm{H}_{6} \mathrm{O}_{3}$ & 6.2 & 137.0234 & 7 & $137.02(100), 93.06(6), 108.93(1)$ \\
Coumaric acid & $\mathrm{C}_{9} \mathrm{H}_{8} \mathrm{O}_{3}$ & 8.86 & 163.0396 & 3 & $118.99(100), 142.99(3), 162(2), 163.03(1)$ \\
Gallic acid & $\mathrm{C}_{7} \mathrm{H}_{6} \mathrm{O}_{5}$ & 2.49 & 169.0139 & 2 & $125.02(100), 169.02(80), 81.032(2)$ \\
Kaempferol & $\mathrm{C}_{15} \mathrm{H}_{10} \mathrm{O}_{6}$ & 15.79 & 285.0411 & 2 & $285.05(100), 151.10(1)$ \\
Luteolin & $\mathrm{C}_{15} \mathrm{H}_{10} \mathrm{O}_{6}$ & 13.12 & 285.0412 & 3 & $285.05(100), 257.07(24), 244.04(2), 167.53(2)$ \\
Eriodictyol & $\mathrm{C}_{15} \mathrm{H}_{12} \mathrm{O}_{6}$ & 13.40 & 287.0566 & 2 & $151.00(100), 287.05(20), 181.61(13)$ \\
Catechin & $\mathrm{C}_{15} \mathrm{H}_{14} \mathrm{O}_{6}$ & 6.51 & 289.0719 & 0 & $174.95(100), 158.97(52), 289.07(30), 245.08(28)$ \\
Quercetin & $\mathrm{C}_{15} \mathrm{H}_{10} \mathrm{O}_{7}$ & 13.71 & 301.0357 & 1 & $301.03(100), 151.00(19), 178.99(10), 255.05(6)$ \\
Taxifolin & $\mathrm{C}_{15} \mathrm{H}_{12} \mathrm{O}_{7}$ & 10.11 & 303.0517 & 2 & $285.04(100), 125.02(30), 303.05(20)$ \\
Myricetin & $\mathrm{C}_{15} \mathrm{H}_{10} \mathrm{O}_{8}$ & 11.65 & 317.0307 & 1 & $317.03(100), 178.99(10), 141.06(8), 227.54(7)$ \\
\hline
\end{tabular}




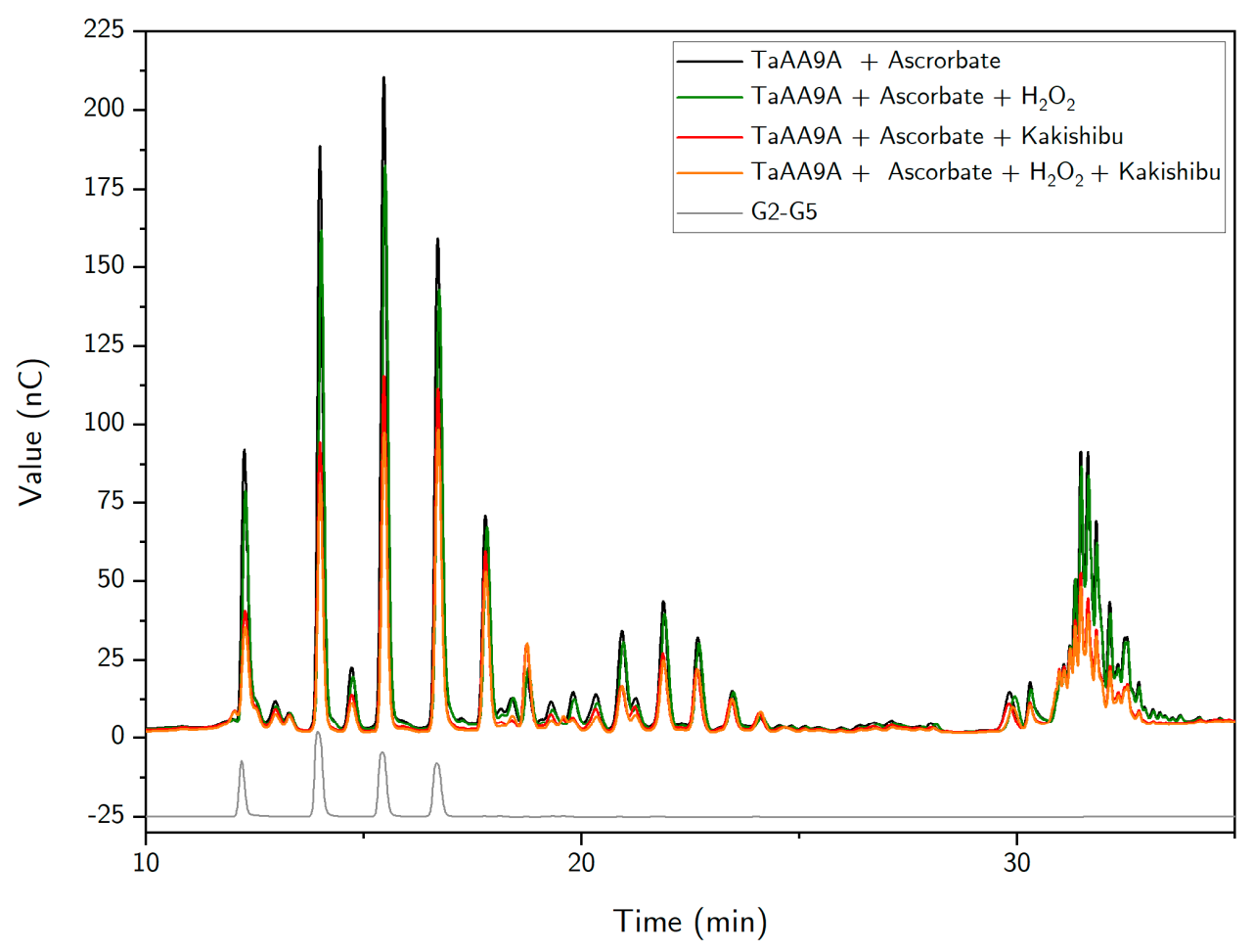

Figure A1. HPAEC chromatogram of TaAA9A inhibition by Kakishibu, in the absence or presence of $\mathrm{H}_{2} \mathrm{O}_{2}$. The effect of Kakishibu (1 mg/mL) was assessed during degradation of PASC $(5 \mathrm{mg} / \mathrm{mL})$ by TaAA9A $(1 \mu \mathrm{M})$. Data are shown in the presence of ascorbate (black), ascorbate and $\mathrm{H}_{2} \mathrm{O}_{2}$ (green), ascorbate and Kakishibu (red) and ascorbate, $\mathrm{H}_{2} \mathrm{O}_{2}$ and Kakishibu (orange). No chromatographic peaks were detected in Kakishibu negative control on this scale and it was, therefore, omitted for the purpose of clarity. Experiments were performed at $50{ }^{\circ} \mathrm{C}$, with ascorbate $(2 \mathrm{mM})$ and $/$ or $\mathrm{H}_{2} \mathrm{O}_{2}$ $(100 \mu \mathrm{M})$. The representative chromatograms show results of the analysis of soluble sugar products by HPAEC-PAD. Non-oxidized products (cellobiose-cellopentaose) appear in the range 12-17 $\mathrm{min}$, confirmed by pure standards (G2-G5, grey). C1-oxidized products are expected to be in the range 18-25 min, while C4- and mixed-oxidation products in the range 30-35 min.

\section{References}

1. Yaqub, S.; Farooq, U.; Shafi, A.; Akram, K.; Murtaza, M.A.; Kausar, T.; Siddique, F. Chemistry and Functionality of Bioactive Compounds Present in Persimmon. J. Chem. 2016, 2016, 3424025. [CrossRef]

2. Perez-Burillo, S.; Oliveras, M.; Quesada, J.; Rufián-Henares, J.; Pastoriza, S. Relationship between composition and bioactivity of persimmon and kiwifruit. Food Res. Int. 2018, 105, 461-472. [CrossRef]

3. Ito, S.; Oshima, Y. Studies on the Tannin of Japanese Persimmon (Diospyros Kaki L.). Agric. Biol. Chem. 1962, $26,156-161$. [CrossRef]

4. Okonogi, T.; Hattori, Z.; Ogiso, A.; Mitsui, S. Detoxification by persimmon tannin of snake venoms and bacterial toxins. Toxicon 1979, 17, 524-527. [CrossRef]

5. McRae, J.M.; Falconer, R.J.; Kennedy, J.A. Thermodynamics of Grape and Wine Tannin Interaction with Polyproline: Implications for Red Wine Astringency. J. Agric. Food Chem. 2010, 58, 12510-12518. [CrossRef]

6. Mandels, M.; Reese, E.T. Inhibition of Cellulases. Annu. Rev. Phytopathol. 1965, 3, 85-102. [CrossRef]

7. Xue, Y.-L.; Miyakawa, T.; Hayashi, Y.; Okamoto, K.; Hu, F.; Mitani, N.; Furihata, K.; Sawano, Y.; Tanokura, M. Isolation and Tyrosinase Inhibitory Effects of Polyphenols from the Leaves of Persimmon, Diospyros kaki. J. Agric. Food Chem. 2011, 59, 6011-6017. [CrossRef]

8. Kracher, D.; Andlar, M.; Furtmüller, P.G.; Ludwig, R. Active-site copper reduction promotes substrate binding of fungal lytic polysaccharide monooxygenase and reduces stability. J. Biol. Chem. 2018, 293, 1676-1687. [CrossRef] [PubMed]

9. Tokin, R.; Frandsen, K.E.H.; Ipsen, J.Ø.; Leggio, L.L.; Poojary, M.M.; Berrin, J.; Grisel, S.; Brander, S.; Jensen, P.E.; Johansen, K.S. Inhibition of lytic polysaccharide monooxygenase by natural plant extracts. New Phytol. 2021, 232, 1337-1349. [CrossRef] 
10. Harris, P.V.; Welner, D.; McFarland, K.C.; Re, E.; Poulsen, J.-C.N.; Brown, K.; Salbo, R.; Ding, H.; Vlasenko, E.; Merino, S.; et al. Stimulation of Lignocellulosic Biomass Hydrolysis by Proteins of Glycoside Hydrolase Family 61: Structure and Function of a Large, Enigmatic Family. Biochemistry 2010, 49, 3305-3316. [CrossRef]

11. Beeson, W.T.; Phillips, C.M.; Cate, J.H.D.; Marletta, M.A. Oxidative Cleavage of Cellulose by Fungal Copper-Dependent Polysaccharide Monooxygenases. J. Am. Chem. Soc. 2012, 134, 890-892. [CrossRef]

12. Phillips, C.M.; Beeson, W.T.; Cate, J.H.; Marletta, M.A. Cellobiose Dehydrogenase and a Copper-Dependent Polysaccharide Monooxygenase Potentiate Cellulose Degradation by Neurospora crassa. ACS Chem. Biol. 2011, 6, 1399-1406. [CrossRef]

13. Nierman, W.C.; Pain, A.; Anderson, M.J.; Wortman, J.; Kim, H.; Arroyo, J.; Berriman, M.; Abe, K.; Archer, D.B.; Bermejo, C.; et al. Genomic sequence of the pathogenic and allergenic filamentous fungus Aspergillus fumigatus. Nat. Cell Biol. 2005, 438, 1151-1156. [CrossRef]

14. Simmons, T.J.; Frandsen, K.E.H.; Ciano, L.; Tryfona, T.; Lenfant, N.; Poulsen, J.C.; Wilson, L.F.L.; Tandrup, T.; Tovborg, M.; Schnorr, K.; et al. Structural and electronic determinants of lytic polysaccharide monooxygenase reactivity on polysaccharide substrates. Nat. Commun. 2017, 8, 1064. [CrossRef]

15. Tokin, R.; Ipsen, J.Ø.; Westh, P.; Johansen, K.S. The synergy between LPMOs and cellulases in enzymatic saccharification of cellulose is both enzyme- and substrate-dependent. Biotechnol. Lett. 2020, 42, 1975-1984. [CrossRef] [PubMed]

16. Teter, S.; Ward, C.; Cherry, J.; Jones, A.; Harris, P.; Yi, J. Variants of Glycoside Hydrolases. U.S. Patent 8383385, 26 February 2013.

17. Bennati-Granier, C.; Garajova, S.; Champion, C.; Grisel, S.; Haon, M.; Zhou, S.; Fanuel, M.; Ropartz, D.; Rogniaux, H.; Gimbert, I.; et al. Substrate specificity and regioselectivity of fungal AA9 lytic polysaccharide monooxygenases secreted by Podospora anserina. Biotechnol. Biofuels 2015, 8, 90. [CrossRef] [PubMed]

18. Filiatrault-Chastel, C.; Navarro, D.; Haon, M.; Grisel, S.; Herpoël-Gimbert, I.; Chevret, D.; Fanuel, M.; Henrissat, B.; HeissBlanquet, S.; Margeot, A.; et al. AA16, a new lytic polysaccharide monooxygenase family identified in fungal secretomes. Biotechnol. Biofuels 2019, 12, 55. [CrossRef] [PubMed]

19. Kruer-Zerhusen, N.; Alahuhta, M.; Lunin, V.V.; Himmel, M.E.; Bomble, Y.J.; Wilson, D.B. Structure of a Thermobifida fusca lytic polysaccharide monooxygenase and mutagenesis of key residues. Biotechnol. Biofuels 2017, 10, 243. [CrossRef] [PubMed]

20. Hernández-Rollán, C.; Falkenberg, K.B.; Rennig, M.; Bertelsen, A.B.; Ipsen, J.Ø.; Brander, S.; Daley, D.O.; Johansen, K.S.; Nørholm, M.H.H. LyGo: A Platform for Rapid Screening of Lytic Polysaccharide Monooxygenase Production. ACS Synth. Biol. 2021, 10, 897-906. [CrossRef] [PubMed]

21. Barkholt, V.; Jensen, A.L. Amino acid analysis: Determination of cysteine plus half-cystine in proteins after hydrochloric acid hydrolysis with a disulfide compound as additive. Anal. Biochem. 1989, 177, 318-322. [CrossRef]

22. Brander, S.; Horvath, I.; Ipsen, J.Ø.; Peciulyte, A.; Olsson, L.; Hernández-Rollán, C.; Nørholm, M.H.H.; Mossin, S.; Leggio, L.L.; Probst, C.; et al. Biochemical evidence of both copper chelation and oxygenase activity at the histidine brace. Sci. Rep. 2020, 10, 16369. [CrossRef]

23. Lever, M. Colorimetric and fluorometric carbohydrate determination with p-hydroxybenzoic acid hydrazide. Biochem. Med. 1973, 7, 274-281. [CrossRef]

24. Quinlan, R.J.; Sweeney, M.D.; Leggio, L.L.; Otten, H.; Poulsen, J.-C.N.; Johansen, K.; Krogh, K.B.R.M.; Jørgensen, C.I.; Tovborg, M.; Anthonsen, A.; et al. Insights into the oxidative degradation of cellulose by a copper metalloenzyme that exploits biomass components. Proc. Natl. Acad. Sci. USA 2011, 108, 15079-15084. [CrossRef] [PubMed]

25. Besharati, M.; Taghizadeh, A. Effect of Tannin-Binding Agents (Polyethylene Glycol and Polyvinylpyrrolidone) Supplementation on In Vitro Gas Production Kinetics of Some Grape Yield Byproducts. Int. Sch. Res. Not. 2011, 2011, 780540. [CrossRef]

26. Tanner, G.J.; Moore, A.E.; Larkin, P.J. Proanthocyanidins inhibit hydrolysis of leaf proteins by rumen microflora in vitro. Br. J. Nutr. 1994, 71, 947-958. [CrossRef]

27. Goldstein, J.L.; Swain, T. The inhibition of enzymes by tannins. Phytochemistry 1965, 4, 185-192. [CrossRef]

28. Olsen, S.; Bohlin, C.; Murphy, L.; Borch, K.; McFarland, K.; Sweeny, M.; Westh, P. Effects of non-ionic surfactants on the interactions between cellulases and tannic acid: A model system for cellulase-poly-phenol interactions. Enzym. Microb. Technol. 2011, 49, 353-359. [CrossRef] [PubMed]

29. Chávez-González, M.; Rodríguez-Durán, L.V.; Balagurusamy, N.; Prado-Barragán, A.; Rodríguez, R.; Contreras, J.C.; Aguilar, C.N. Biotechnological Advances and Challenges of Tannase: An Overview. Food Bioprocess. Technol. 2011, 5, 445-459. [CrossRef]

30. Bissaro, B.; Røhr, Å.K.; Müller, G.; Chylenski, P.; Skaugen, M.; Forsberg, Z.; Horn, S.J.; Vaaje-Kolstad, G.; Eijsink, V.G.H. Oxidative cleavage of polysaccharides by monocopper enzymes depends on $\mathrm{H}_{2} \mathrm{O}_{2}$. Nat. Chem. Biol. 2017, 13, 1123-1128. [CrossRef] [PubMed]

31. Calderaro, F.; Keser, M.; Akeroyd, M.; Bevers, L.E.; Eijsink, V.G.H.; Várnai, A.; Berg, M.A.V.D. Characterization of an AA9 LPMO from Thielavia australiensis, TausLPMO9B, under industrially relevant lignocellulose saccharification conditions. Biotechnol. Biofuels 2020, 13, 195. [CrossRef] [PubMed]

32. Brander, S.; Tokin, R.; Ipse2, J.Ø.; Jensen, P.E.; Hernández-Rollán, C.; Nørholm, M.H.H.; Leggio, L.L.; Dupree, P.; Johansen, K.S. Scission of Glucosidic Bonds by a Lentinus similis LPMO is Strictly Dependent on $\mathrm{H}_{2} \mathrm{O}_{2}$ While Oxidation of Saccharide Products Depends on O2. ASC Catal. 2021, 11, 13848-13859.

33. Mandels, M.; Reese, E.T. Inhibition of cellulases and $\beta$-glucosidases. In Advances in Enzymic Hydrolysis of Cellulose and Related Materials; Elsevier BV: Amsterdam, The Netherlands, 1963; pp. 115-157. 
34. Lee, Y.A.; Cho, E.J.; Tanaka, T.; Yokozawa, T. Inhibitory Activities of Proanthocyanidins from Persimmon against Oxidative Stress and Digestive Enzymes Related to Diabetes. J. Nutr. Sci. Vitaminol. 2007, 53, 287-292. [CrossRef]

35. Ximenes, E.; Kim, Y.; Mosier, N.; Dien, B.; Ladisch, M. Deactivation of cellulases by phenols. Enzym. Microb. Technol. 2011, 48, 54-60. [CrossRef] [PubMed]

36. Ximenes, E.; Kim, Y.; Mosier, N.; Dien, B.; Ladisch, M. Inhibition of cellulases by phenols. Enzym. Microb. Technol. 2010, 46, 170-176. [CrossRef]

37. Ramawat, K.G.; Mérillon, J.M. Natural Products; Springer: Berlin/Heidelberg, Germany, 2013; ISBN 978-3-642-22143-9.

38. Börjesson, J.; Engqvist, M.; Sipos, B.; Tjerneld, F. Effect of poly(ethylene glycol) on enzymatic hydrolysis and adsorption of cellulase enzymes to pretreated lignocellulose. Enzym. Microb. Technol. 2007, 41, 186-195. [CrossRef]

39. Feng, X. Methods of Reducing the Inhibitory Effect of a Tannin on the Enzymatic Hydrolysis of Cellulosic Material. CN101910405A, 8 December 2010.

40. Frommhagen, M.; Mutte, S.K.; Westphal, A.H.; Koetsier, M.J.; Hinz, S.W.A.; Visser, J.; Vincken, J.-P.; Weijers, D.; Van Berkel, W.J.H.; Gruppen, H.; et al. Boosting LPMO-driven lignocellulose degradation by polyphenol oxidase-activated lignin building blocks. Biotechnol. Biofuels 2017, 10, 121. [CrossRef]

41. Lu, M.-J.; Chu, S.-C.; Yan, L.; Chen, C. Effect of tannase treatment on protein-tannin aggregation and sensory attributes of green tea infusion. LWT 2009, 42, 338-342. [CrossRef]

42. Adamczyk, B.; Simon, J.; Kitunen, V.; Adamczyk, S.; Smolander, A. Tannins and Their Complex Interaction with Different Organic Nitrogen Compounds and Enzymes: Old Paradigms versus Recent Advances. ChemistryOpen 2017, 6, 610-614. [CrossRef] [PubMed]

43. Labuckas, D.; Maestri, D.; Lamarque, A. Molecular Characterization, Antioxidant and Protein Solubility-Related Properties of Polyphenolic Compounds from Walnut (Juglans regia). Nat. Prod. Commun. 2016, 11, 637-640. [CrossRef]

44. Harbertson, J.F.; Kilmister, R.L.; Kelm, M.A.; Downey, M.O. Impact of condensed tannin size as individual and mixed polymers on bovine serum albumin precipitation. Food Chem. 2014, 160, 16-21. [CrossRef]

45. Hagerman, A.; Butler, L. The specificity of proanthocyanidin-protein interactions. J. Biol. Chem. 1981, 256, 4494-4497. [CrossRef]

46. Kont, R.; Pihlajaniemi, V.; Borisova, A.S.; Aro, N.; Marjamaa, K.; Loogen, J.; Büchs, J.; Eijsink, V.G.H.; Kruus, K.; Väljamäe, P. The liquid fraction from hydrothermal pretreatment of wheat straw provides lytic polysaccharide monooxygenases with both electrons and $\mathrm{H}_{2} \mathrm{O}_{2}$ co-substrate. Biotechnol. Biofuels 2019, 12, 235. [CrossRef] [PubMed] 